\title{
Identifying Student Potential for ICT Entrepreneurship using Myers-Briggs Personality Type Indicators
}

\author{
Kevin A. Johnston, Barry K. Andersen, Jennifer Davidge-Pitts, \\ and Mark Ostensen-Saunders \\ University of Cape Town, Cape Town, South Africa
}

Kevin.Johnston@uct.ac.za; barryandersen@gmail.com; jenniferdpitts@gmail.com; m ostensen saunders@hotmail.com

\section{Executive Summary}

Literature relating to personality and entrepreneurship has focused primarily on personality characteristics of traditional entrepreneurs. The focus of this study was on personality characteristics and temperaments of potential Information and Communication Technology (ICT) entrepreneurs.

The main objective of the study was to evaluate the efficacy of personality characteristics as identifiers of potential ICT entrepreneurship. The personality characteristics of the participants were measured on the Keirsey Temperament Sorter, a proven research instrument. Two entrepreneurial tests were used to determine entrepreneurial ability. The temperament of the individuals was ascertained and compared to their entrepreneurial ability. The population sample used for this study was comprised of third year and honours information systems students from the University of Cape Town and current ICT entrepreneurs.

A positive relationship between the rational and idealist temperaments and potential ICT entrepreneurs was found. No significant relationship between specific personality types and potential entrepreneurial ability were evident in the study.

A positive connection was noticed between potential ICT entrepreneurs and being male. Unfortunately the number of female respondents was insufficien to lead to a conclusive result.

Keywords: Temperament, personality, entrepreneurial tests, entrepreneurs, Information and Communication Technology (ICT).

\section{Introduction}

Research shows that the success of an entrepreneurial individual has often been correlated with his/her personality type (Markman \& Baron, 2003). Due to the rapid development of Information

Material published as part of this publication, either on-line or in print, is copyrighted by the Informing Science Institute. Permission to make digital or paper copy of part or all of these works for personal or classroom use is granted without fee provided that the copies are not made or distributed for profit or commercial advantage AND that copies 1) bear this notice in full and 2) give the full citation on the first page. It is permissible to abstract these works so long as credit is given. To copy in all other cases or to republish or to post on a server or to redistribute to lists requires specific permission and payment of a fee. Contact Publisher@InformingScience.org to request redistribution permission. and Communication Technology (ICT) entrepreneurs, research dealing with specifics, such as the significance of personality types and the potential ICT entrepreneur, has largely been ignored. There is a need to identify potential ICT entrepreneurs, as entrepreneurship can allow limited resources to be utilised effectively, increasing job creation within an economy. Entrepreneurship plays an important role in creating 
competitive advantage for organisations and thus facilitating their survival and growth (Chen, Zhu, \& Anquan, 2005; Echols \& Neck, 1998). This is true for all areas of the world including Africa. Fick (2002, p3) states that, "While there are often huge differences in their climate, culture, and traditions and in their political and economic systems, countries in Africa are often confronted by similar problems and challenges." In an investigation into problems facing smallto-medium sized enterprises in achieving growth in a province of South Africa, Sha (2006) highlights weaknesses in innovation and entrepreneuship among others.

The objectives of this research are:

- To find a means of identifying potential entrepreneurs.

- To determine whether there is a significant correlation between a specific personality type/temperament and the aptitude of individuals to being ICT entrepreneurs.

- To identify the most prominent traits and temperaments of potential ICT entrepreneurs.

- To determine if there is a significant correlation between potential ICT entrepreneurs and gender.

The report attempts to identify potential entrepreneurs through their personality type/temperament. Participants were 3rd and 4th year Information System students at the University of Cape Town and young entrepreneurs in the ICT industry.

The paper reviews literature that covers: entrepreneurs, information and communication technology (ICT), personality testing, personality types, and gender issues relating to entrepreneurship. This is followed by an overview of the objectives of this research and the methodologies used to accomplish these objectives. Analysis of the data follows, and the derived findings are reported. Finally, the report discusses the conclusions identified in the findings, and makes recommendations for further research.

\section{Background}

Typically, an entrepreneur will discover an opportunity, marshal resources, and organise these into a venture that offers some innovation into the market. Entrepreneurs essentially act as agents for change and wealth creation (Rwigema \& Venter, 2004). Entrepreneurs face many significant challenges, not the least of which is generating or recognising ideas that have the potential to be developed into appealing goods and services. Successful ideas are often a balance between novelty and familiarity (Ward, 2004). Information and Communication Technology (ICT) entrepreneurs are a new variation of the traditional entrepreneur.

Deo (2005) defines an entrepreneur from two different viewpoints: that of an economist and a psychologist:

1. "To an economist, an entrepreneur is one who brings resources, labour, materials and other assets into combinations that makes their value greater than before, and also one who introduces changes, innovations, and a new order."

2. "To a psychologist, such a person is typically driven by certain forces-the need to obtain or attain something, to experiment, to accomplish, or perhaps to escape the authority of others."

This paper focus on the psychological viewpoint.

While entrepreneurs have much in common, they also differ widely. There is no single set of attitudes and behaviours that every entrepreneur must have. What is required in each situation, depends on a mix of key players and how promising and forgiving the opportunity is, given the 
founder's strengths and shortcomings (Timmons, 1999). Although this is true, a study found that successful entrepreneurs tend to share certain traits (Hendriks, Nhlapo, \& Samodien, 2002). Some of the key traits of a successful entrepreneur as found by Hendriks et al. include innovativeness, initiative, achievement drive, willingness to take calculated risks, flexibility, and competitiveness.

Entrepreneurs are often described according to their personal characteristics or personality and the social and institutional context in which they operate (Chell, Haworth, \& Brearley, 1991). Recent psychological and sociological approaches to entrepreneurship stress the importance of a multi-disciplinary nature of the individual, and many researchers have concentrated upon particular qualities or attitudes, motivations, being a leader, or social forces (Mcquaid, 2002).

Rwigema and Venter (2004) conducted research and found that the following traits were commonly exhibited in an entrepreneur: commitment, self-reliance, tenacity, a need to achieve, opportunity drive, initiative, responsibility, problem solving abilities, and team building abilities. After undertaking a study based on interviewing business-people who had succeeded in an entrepreneurial role, Howorth, Tempest, and Coupland (2005) found that it is difficult to narrow down the qualities that make an entrepreneur.

Entrepreneurs are identified not only through their personality or characteristics. It is also important to consider what an entrepreneur does, instead of merely who they are. It is therefore imperative to consider entrepreneurship as a form of behaviour and not merely a collection of common characteristics (Mcquaid, 2002). Unlike the traditional business owner or manager, who is often obsessed with resources they control, entrepreneurs are strategically orientated and pursue opportunities (Mcquaid, 2002).

According to Ma and Tan (2006), the attempt to determine the psychological profile of an entrepreneur is bound to fail because, for each of the traditional definitions of the entrepreneurial type, there are numerous counter examples that disprove the theory. Ma and Tan argue that the macro view of entrepreneurship is insufficient as environmental factors cannot be examined independently of psychological factors.

Drucker (as quoted in Mcquaid, 2002) argued that entrepreneurship is a form of behaviour that can be learnt through practice of systematic innovation, which consists of a systematic analysis of opportunities, and a search for changes that may suggest innovation. This suggests that entrepreneurs include those who exhibit such behaviour and systematically analyse and grasp opportunities arising from developments, therefore, building upon their experiential learning (Mcquaid, 2002).

Many entrepreneurs hold similar personal characteristics (Mcquaid, 2002). As a result of these common characteristics, people may assume that entrepreneurs possess similar personalities. Many tests have been formulated to understand and compute an individual's personality. Keirsey's Temperament Sorter is one of these tests and is often used to draw a correlation between certain personality types and career options (Schwalbe, 2006).

Psychological assessments within the ICT industry are now commonly performed through the use personality assessment tools, one of which is the Keirsey Temperament Sorter (Keirsey \& Bates, 1998; Schwalbe, 2006). The Keirsey Temperament Sorter is a common indicator of an individual's temperament and has been used as a tool for research and as a test for personalityorganisation fit (Markman \& Baron, 2003). The Keirsey Temperament Sorter is derived from the Myers Briggs Type Indicator (MBTI) which is based on Jung's personality types (Pittenger, 1993). Borg and Shapiro (1996) noted that the MBTI is widely used in research that investigates personality types, and it is relatively easy to administer through an individual indicating their preferences on a questionnaire. 
A personality is made up of an individual's temperament and character. Temperament is a configuration of inclinations, while character is a configuration of habits (Keirsey \& Bates, 1998). The Keirsey Temperament Sorter, like the MBTI, measures eight personality type variables in four dimensions: extravert-introvert, sensing-intuition, thinking-feeling, and judgementperception (Keirsey \& Bates, 1998). These are summarized in Table 1. Although no person uses only one personality type within a dimension (eg. sensing-intuition), "each person has a preference for one or the other and has developed that process more fully, and thus it has become dominant in his or her personality type" (Borg \& Shapiro, 1996). The Keirsey Temperament Sorter requires an individual to select between 70 dichotomous words or phrases. The result is an indication of a person's personality type (MBTI) within the four dimensions; for example, if a person scores higher on Introvert than Extrovert, and higher on Sensing, Thinking and Judgement, they would be classified as an ISTJ personality type.

\section{Attitude to Life (E/I) \\ E: Extroversion}

The person's interest flows mainly to the outer world of actions, objects, and persons.

\section{Method of Perception (S/N)}

\section{S: Sensing}

The person prefers to perceive the immediate, real, practical fact of experience and life.

\section{I: Introversion}

The person's interest flows mainly to the inner world of concepts and ideas.

\section{N: Intuition}

The person prefers to perceive the possibilities, relationships, and meanings of experiences.

\section{Method of Judgement (T/F)}

\section{T: Thinking}

\section{F: Feeling}

The person prefers to make judgments and deci- The person prefers to make judgments or decisions objectively, impersonally, considering sions subjectively and personally, weighing valcauses of events and where decisions may lead. ues of choices and how they matter to others.

\section{Lifestyle (J/P)}

\section{J: Judgment}

The person prefers mostly to live in a decisive, planned, and orderly way, aiming to regulate and control events.

\section{P: Perception}

The person prefers mostly to live in a spontaneous, flexible way, aiming to understand life and adapt to it.

\section{Table 1: The Four Preferences That Are Scored to Arrive at a Person's Personality Type (Borg \& Shapiro, 1996)}

Temperament is the inborn foundation on which personality is built (Hendriks et al., 2002). Temperament Theory is based on four basic patterns that have been consistently and cross culturally recognised in the human personality. Although individuals may share similar core values and needs, it does not imply that they are the same (Keirsey \& Bates, 1998). The four temperaments that Keirsey \& Bates (1998) identified are:

- Artisans - Live one day at a time, and can be classified by the following personality types: ESTP, ISTP, ESFP, ISFP.

- Guardians - Are driven by responsibility, and possess one of the following personality types: ESTJ, ISTJ, ESFJ, ISFJ.

- Rationals -Seek knowledge and competence in all they take on, and can be recognised by the following personality types: ENTJ, INTJ, ENTP, INTP. 
- Idealists - Are soul searchers who constantly quest for meaning and significance in their lives, with the following personality types: ENFJ, INFJ, ENFP, INFP.

Keirsey and Bates (1998) divided the four temperaments into two groups: "Earthlings" which consisted of Artisans and Guardians, and "Martians" which consisted of Rationals and Idealists. A typical ICT professional is usually ISTJ or INTJ (logical, analytical, dependable, organised, systematic) and inflexible, weak communicator, resistant to change (Schwalbe, 2006).

ICT has traditionally been a male dominated industry. Although different causal factors may certainly be involved, much research has tacitly assumed a unitary factor leading to the low levels of women in ICT. This factor is simplified to a negative computer attitude in females (Haliburton, Thweatt, \& Wahl, 1998).

Many women face a career "glass ceiling" and, therefore, start new ventures at a higher rate than men (Rwigema \& Venter, 2004), and the Internet has provided a new and powerful means for that matter (Lorek, 2001). For example, in the developing world, the use of ICT and e-commerce seems to be particularly attractive to women owning small enterprises. These female entrepreneurs are now able to use ICT to identify new business opportunities or communicate with potential clients. New IT businesses run by women have emerged along the models of teleboutiques or telecentres of Senegal and Morocco, phone shops in Ghana, Internet cafes or kiosks in Thailand and Malaysia, and the Grameen Phone in Bangladesh (Teltscher, 2002).

The UK Government had a drive led by Equality Minister Jacqui Smith to increase the number of female owned businesses to 20 per cent by 2006 (Seeda, 2005). A report by Startups (2004) stated that $1.5 \%$ of women were entrepreneurs in the South East of the UK. Richardson (2004) noted that the Equal Opportunities Commission (EOC) carried out an investigation to discover why there were so few women $(20 \%)$ working in the ICT sector in the UK.

\section{Research Method}

Following the literature reviewed, the following hypotheses were established:

- H1: Personality characteristics and temperaments of ICT individuals, as measured by personality tests and questionnaires, are effective predictors of the aptitude of individuals to being ICT entrepreneurs.

Various authors found that entrepreneurs tend to share certain personality characteristics, temperaments and traits (Chell et al., 1991; Hendriks et al., 2002; Mcquaid, 2002; Rwigema $\&$ Venter, 2004). Keirsey's Temperament Sorter is a test used to attempt to understand a person's personality and is often used to draw a correlation between certain personality types and career options (Schwalbe, 2006). Thus it appears that such a test might be used to effectively identify the aptitude of individuals likely to become ICT entrepreneurs.

- H2: Males are more likely to be potential ICT entrepreneurs.

The ICT marketplace is dominated by males (Haliburton et al., 1998; Richardson, 2004), as is the entrepreneurial marketplace (European Database Records, 2003). It thus appears that one could expect males to dominate in the ICT entrepreneurial space.

Our methodology was to use proven instruments to identify entrepreneurial aptitude among ICT personnel, and then to correlate this aptitude with the results of established Meyers-Briggs type personality tests. Since eight temperamental inclinations have been defined by the literature, typing these to ICT personnel who test highly for entrepreneurial aptitude would enable us to conclude that certain temperaments among ICT personnel were an indicator of potential ICT aptitude. 
Three groups of participants were identified. The first group consisted of third year students with a variety of majors taking an Information Systems course at the University of Cape Town (UCT). The research sample consisted only of those 91 students who completed both the personality test and the two entrepreneurial ability tests. The second group within the sample included honours students majoring in ICT at UCT, resulting in an additional sample of 19 students. Finally the sample included 25 responses from current ICT entrepreneurs who have recently started their own business. The response rate was almost $80 \%$.

When considering the three groups of participants, it is important to note that our goal for this particular study was not to compare ICT students with entrepreneurs. Rather, our aim was to obtain a sufficient number of participants among the entire study population who would score sufficiently highly on the entrepreneurial aptitude test to allow us to correlate this aptitude with each of the eight possible temperaments defined by the literature.

Three questionnaires were chosen as the research instruments. Using questionnaires allowed for a greater number of participants to be analysed and offered participants a degree of anonymity. Questionnaires proved to be more convenient for ICT entrepreneurs with demanding schedules, as they were able to complete them in their own time.

The three instruments used during the research included two instruments to measure entrepreneurial ability and one instrument to measure the eight temperaments. To measure temperaments, we used a version of the Keirsey Temperament Sorter. This was comprised of seventy questions that required participants to choose between two opposing statements that inconspicuously relate to their personality; these responses produce a personality profile. The results from this temperament sorter were used to evaluate the characteristics of the participants' personalities by allocating scores for the respondents on eight personality dimensions, each of which consisted of two opposing possibilities. The Keirsey Temperament Sorter was selected as it is a proven instrument and has shown successful results in a number of studies, particularly those dealing with the effects of personality on educational outcomes (Borg \& Shapiro, 1996). To measure the validity of the tests performed, factor testing was conducted to ensure that the tests were accurate in measuring personality and potential entrepreneurs.

To measure entrepreneurial ability, we used two proven instruments. The first entrepreneurial test was adapted from the test obtained from Stanford University's online Women's Business Center. This test was selected due to Stanford University's academic credibility, ease of administration of the test, and the fact that it was freely and readily available (Stanford University, 2004). The questionnaire, which assess their entrepreneurial ability, comprised 25 questions that required the participant to choose between three options. The second entrepreneurial test was obtained from the Oxford Science Enterprise Center (Oxford University, 2004). Once again, this test was selected due to the academic credibility of the university, ease of administration, and accessibility of the test (Oxford University, 2004). The test required respondents to identify perceived benefits, in order to evaluate their career preferences against that of an entrepreneur.

All the questionnaires were approved by the University of Cape Town's ethics committee.

\section{Analysis and Findings}

\section{Primary Findings}

Both hypotheses were separately tested for statistical significance. The hypotheses testings were first performed on the entire sample. Due to the expected bias of certain sub samples, these hypotheses were retested on the separate groups within the sample to determine whether there were any significant deviations from the original results. 
Figure 1 shows the distribution of the scores of the respondents from entrepreneurial test 1 , the results do not show a normal distribution, as the histogram is negatively skewed. Investigation revealed that the skewed data was a result of the third year student's biased responses. The third year students had recently attended entrepreneurial lectures and may have felt that it was favourable to be identified as an entrepreneur. They also had knowledge from these recent lectures about the likely characteristics of entrepreneurs, which could allow them to easily outwit this test.

Figure 2 illustrates the distribution of the scores from the respondents for entrepreneurial test 2, a more normal distribution is observed. Entrepreneurial test 2 was therefore more viable as a predictor of potential entrepreneurs among this study population. Hence test 1 was discarded, and only test 2 data used.

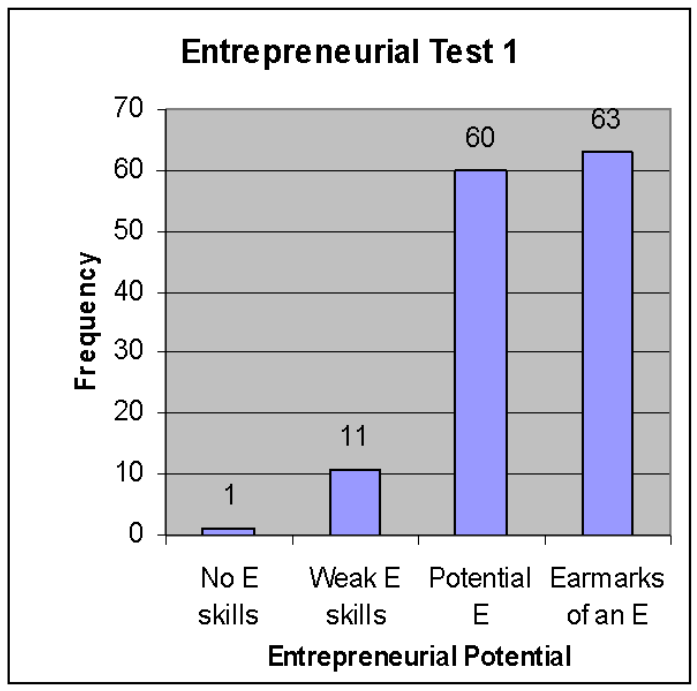

Figure 1: Entrepreneurial Test 1

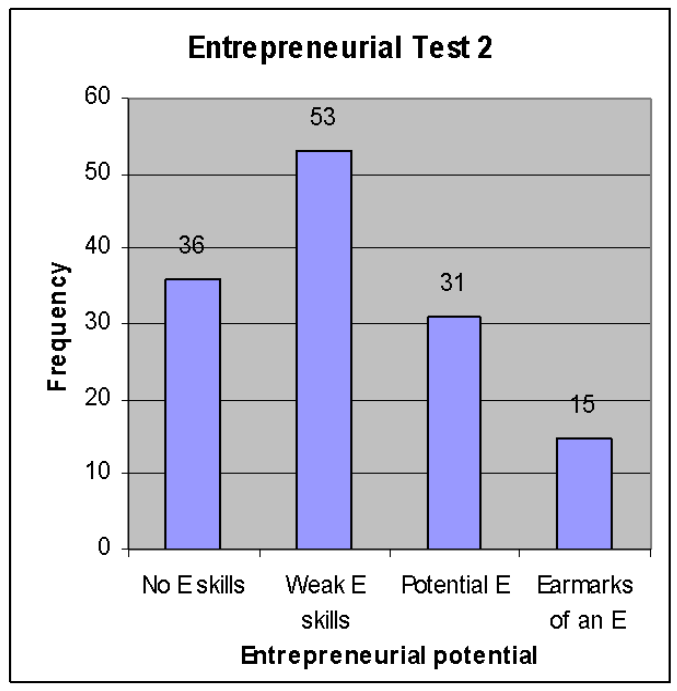

Figure 2: Entrepreneurial Test 2

The final personality traits are believed to be an indication of preference. Among this study population (all of whom intend to major in IS), the predominant personality type is Judgemental (J) (19\%), Judgement personalities prefer "to live in a decisive, planned, and orderly way, aiming to regulate and control events" (Borg \& Shapiro, 1996, p5).

In Figure3, it can be observed that there is no predominant personality type for respondents; however, it is clear that the Judgemental $(\mathrm{J})$ personality trait is the most predominant. A judging type personality prefers to come to conclusions about what one encounters in the external environment. When related to ICT, they enjoy results of tasks more than the process that leads to the results (Kaluzniacky, 2004). ICT professionals are likely to score higher on the Judgemental personality type given that most ICT projects are structured around particular methodologies that the professionals are familiar with. This environment espouses scheduling of activities, and any interruptions during the process may have negative consequences to the progress of ICT projects. This is unlike the Perceiving personality type that prefers much more open-ended schedules (Kaluzniacky, 2004). 


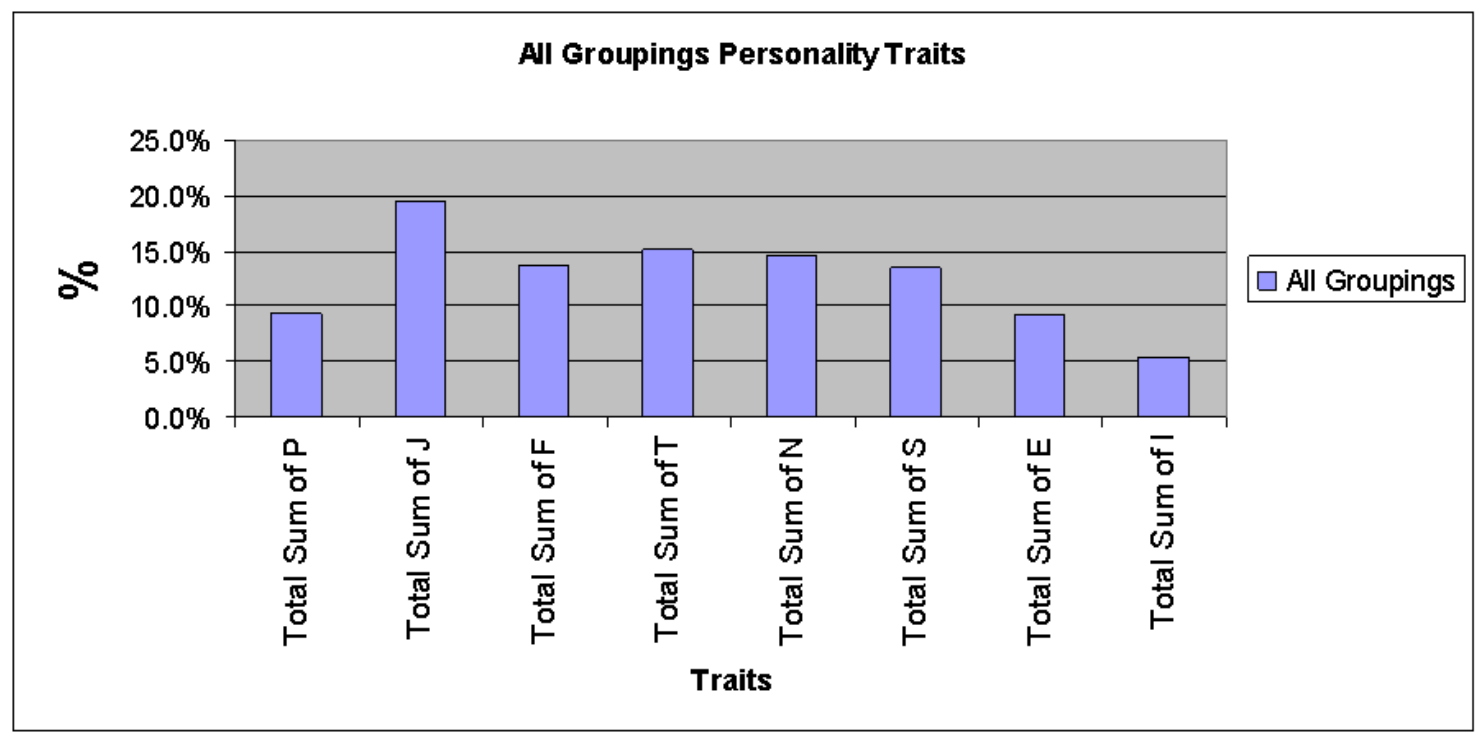

Figure3: Illustration of Personality traits common to the entire sample population

Figure 4 is a summary of the eight personality characteristics for all respondents. Figure 4 shows the distribution of personality traits for each of the groups within the sample, and the relevant proportions between them.

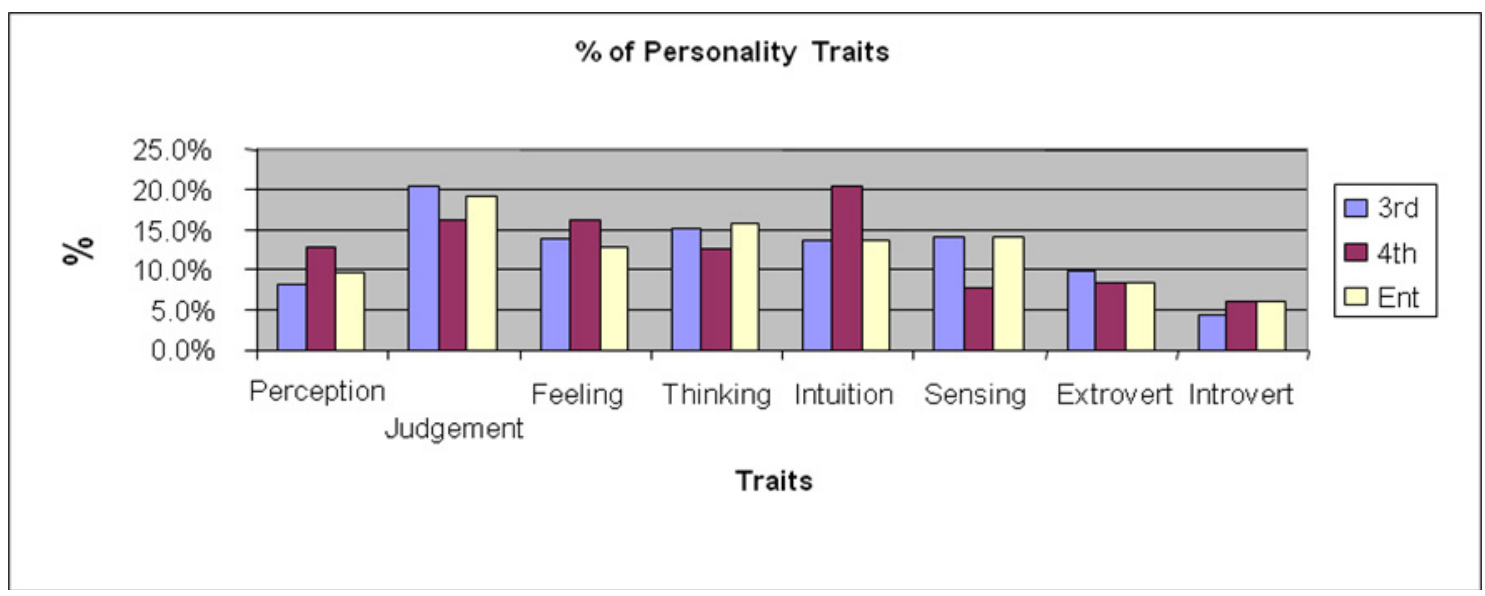

Figure4: Description of Personality traits common to the separate sample populations

Spikes are observed for the Intuitive (N) and Judging (J) characteristics. An interesting observation is that Sensing $(\mathrm{S})$ characteristic slump, and the Perception $(\mathrm{P})$ and Intuitive $(\mathrm{N})$ characteristic show unexpected spikes for the fourth year students. Werth (1986) noted that senior engineering students had a higher percentage of thinking-judging (TJ) than junior students. One uncharacteristic result is where the fourth year (Information Systems majors) are shown to be more intuitive compared to others. In the sample above, third year students comprise students taking various majors, apart from Information Systems. On the other hand, the fourth year students are IS majors whose intentions are to be professionals in that field. Various studies have showed that most IS professionals exhibit a sensing personality type since this perspective reflects the practical, de- 
tails-and-facts-oriented sensing mentality of IS projects (Kaluzniacky, 2004, Lyons, 1998). Therefore, given their career choice the expectation was to see a higher spike for IS majors. A possible reason for this relates to the design of the IS honours course, which is oriented more towards systems planning, high level business and data modeling, object modeling and IS championship in organizations. This is much more oriented towards the intuitive type as revealed by the higher spike for fourth years (Kaluzniacky, 2004).

Another possible explanation can be inferred from the other groups: third years and the entrepreneurs. The sensing feature shows that these two groups have a similar score. Sensing focuses on the real, tangible, and actual aspects. Thus a sensing person is more practical as opposed to imaginary. Entrepreneurs live in a practical and real world and gather information on what is happing around them based on the five senses. Thus the higher sensing spike, relative to intuition, shows this. The third year students' appearance of being more sensing than intuitive may be attributable to the influence of a recent entrepreneurial course they took.

This 'banding' of the entrepreneurs and the third years is also noticeable in the judgement spike, where the percentage is $18 \%$ and $20 \%$ respectively. On the other hand, fourth years scored $15 \%$, which may not be considered to be necessarily significant. The judgement type feature prefers a "planned, organized, structured life, and enjoys results from a task rather than the process that leads to the results" (Kaluzniacky, 2004, p. 5). This focus on results is a hallmark of an entrepreneur's daily life as opposed to the perceiving type who is prone more to live an open-ended life and enjoys more the processes of work tasks. Third years may have been influenced by their entrepreneurial course, while entrepreneurs ascribe to the judgement type due to their need to get results on a daily basis. The influence of the IS course structure may have contributed to the fourth years having a perceiving tendency.

To test hypothesis 1 (Personality characteristics and temperaments of ICT Individuals, as measured by personality tests and questionnaires are effective predictors of potential ICT entrepreneurs) statistically, a correlation matrix was used (Figure 5).

\begin{tabular}{|c|c|c|c|c|c|c|c|c|c|}
\hline & $E$ & I & $S$ & $N$ & $T$ & $F$ & $J$ & $P$ & $\begin{array}{l}\text { Test } \\
2 \text { tot }\end{array}$ \\
\hline$E$ & 1 & & & & & & & & \\
\hline I & -0.99112 & 1 & & & & & & & \\
\hline$S$ & -0.23082 & 0.237933 & 1 & & & & & & \\
\hline $\mathrm{N}$ & 0.115144 & -0.10689 & -0.87472 & 1 & & & & & \\
\hline $\mathrm{T}$ & -0.17136 & 0.197308 & 0.254651 & -0.25296 & 1 & & & & \\
\hline $\mathrm{F}$ & 0.126294 & -0.14222 & -0.21802 & 0.306857 & -0.94189 & 1 & & & \\
\hline$J$ & -0.11111 & 0.113158 & 0.294651 & -0.23169 & 0.32968 & -0.26831 & 1 & & \\
\hline$P$ & 0.090183 & -0.06782 & -0.2657 & 0.258302 & -0.23903 & 0.219221 & -0.94581 & 1 & \\
\hline $\begin{array}{l}\text { Test } \\
2 \text { tot }\end{array}$ & -0.17259 & 0.202086 & -0.07978 & 0.114818 & 0.001532 & 0.021693 & -0.27755 & 0.329851 & 1 \\
\hline
\end{tabular}

Figure 5: Test 2 correlation matrix for personality and potential entrepreneurs

The correlation matrix in Figure 5 shows the correlation between the scores of the temperament traits, as well as the entrepreneur test 2 scores.

For this sample, the calculated level of significance is 0.294884 . The coefficients highlighted reveal weak but significant correlations, which are analyzed below. 
The entrepreneurial test revealed that potential entrepreneurs were $31 \%$ of the sample, while those students identified as entrepreneurial were $15 \%$ of the sample. These two groups make $46 \%$ of the sample. The weak correlations may be attributed to the 'tempering effect' of the $54 \%$ of the sample who showed weak or no entrepreneurial tendencies. Therefore, the discussion of the correlations has taken this into consideration.

There are three notable correlations: between Feeling (F) and iNtuition (N); Judgement (J) andThinking (T); and Entrepreneurship score (Ent) and Perceiving (P). The correlations for the three are $0.31,0.33$ and 0.33 respectively. Entrepreneurship was significantly correlated to Perceiving, even though it is a weak correlation. Entrepreneurs who are highly adaptable have been found to be more Perceiving (Reynierse, 2000) as opposed to highly innovative entrepreneurs who are likely to be more intuitive (Reynierse, 1997). When this result is considered in context, the insight that emerges is that ICT entrepreneurs in South Africa are more likely to be of the adaptable type as opposed to being innovative. This is consistent with the notion that developing countries are a net consumer of technologies that mostly come from the more developed countries. Therefore, ICT entrepreneurs are likely to adapt ICT solutions emerging from developed countries to 'fit' the environment rather develop new novel ICT solutions. The environment in Africa largely remains unexplored, thus the Perceiving type fits in such an environment. The dominant preference in the Perceiving type is being able to notice the outer environment while assessing the possibilities. Given the many possibilities in the African environment yet unexploited, the perceiving type balks from making conclusions (Judging) but rather looks for ways to adapt the environment. The entrepreneurs in these contexts thus become broad-based change agents (Drucker, as quoted in Mcquaid, 2002) due to the many possibilities.

The link between $\mathrm{F}$ and $\mathrm{N}$ suggests a joint contribution of people-centered values $(\mathrm{F})$ while searching for possibilities $(\mathrm{N})$ in entrepreneurial activity.

Therefore, while Perceiving identifies various possibilities, an entrepreneur still needs to focus on an identifiable and feasible ICT opportunity at any one time $(\mathrm{J})$ and this should be arrived at logically $(\mathrm{T})$.

In summary, the findings have not identified a significant personality type that can be used to identify potential ICT entrepreneurs. However, the following combinations of characteristics were found to be the most strongly correlated: Feeling $(\mathrm{F})$ and iNtuition $(\mathrm{N})$; Judgement $(\mathrm{J})$ andThinking (T).

We therefore fail to reject the null hypothesis, but recommend further research on these combinations as actual predictors of ICT entrepreneurship.

Hypothesis two is that males are more likely to be potential entrepreneurs than females.

Figure 6 shows males and females divided into respondents identified as potential entrepreneurs and those identified as non-potential entrepreneurs. Figure 6 illustrates the gender analysis on the potential to become an ICT entrepreneur using test 2 . It shows that there is a greater proportion of non-entrepreneurial females $(89.2 \%)$ to that of males $(61.8 \%)$. Unfortunately this correlation cannot be considered to be significant, as the data is highly skewed with respect to number of males (98) and females (37). Due to the skewed data, no further statistical tests were conducted. 


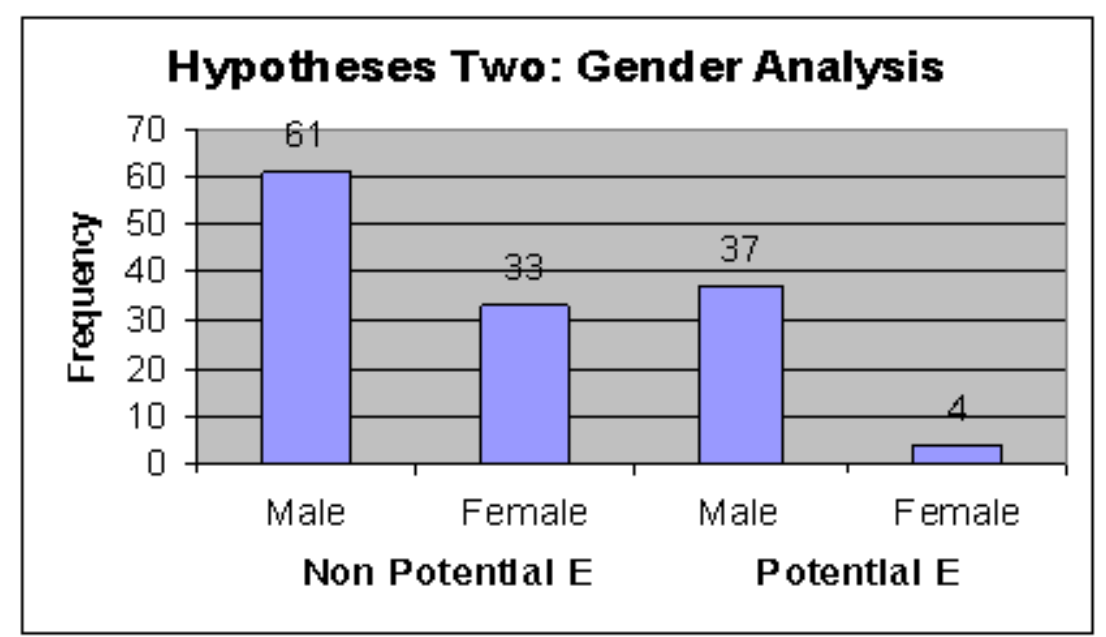

Figure 6: Gender comparison of potential entrepreneurial ability for all respondents

The data suggests that there may be a connection between being male and possessing potential ICT entrepreneurial ability. Due to the skewness of the data collected, this correlation could not be statistically proven and is merely an observation of a trend. Although there are several limitations to the data obtained in relation to the secondary hypothesis, this trend cannot be completely discounted. Due to the unrepresentative data, the statistics are not strong enough to explicitly accept or reject the hypothesis. This however does not imply that there is no correlation between gender and potential ICT entrepreneurial ability. Results are suggestive that males tend to score higher on tests of entrepreneurial aptitude. If this is the case, then it may be because the tests themselves were designed and set up using a predominantly male population, or it may be because the females in this study were less likely to attempt to outwit the instrument and score highly on entrepreneurship, or perhaps males tend to be entrepreneurial at a young age while females tend to become more entrepreneurial as they grow older. All of these are areas for further study in terms of ICT entrepreneurs.

\section{Additional Findings}

In the process of analyzing the data, there were certain results that were not directly used for the evaluation of the hypotheses. The data collected from these results allowed for further analysis which lead to additional findings.

It was noticed that there were significant differences between the three separate groups within the population sample, in terms of their results obtained in the entrepreneurial tests.

Regression analysis comparing test 1 and test 2 scores for the three population samples (3rd years, 4th years, and ICT Entrepreneurs) indicated that there is little correlation between the results of the two entrepreneurial tests, except in the case of the ICT Entrepreneurial group. The R2 value (0.4087) for ICT Entrepreneurs shows that the two entrepreneurial tests are viable identifiers of potential ICT entrepreneurs. Therefore, we recomputed the correlation matrix, for the entrepreneurial group (Figure 7). 
Identifying Student Potential for ICT Entrepreneurship

\begin{tabular}{|c|c|c|c|c|c|c|c|c|c|c|}
\hline & $E$ & $I$ & $s$ & $N$ & $T$ & $F$ & J & $P$ & $\begin{array}{c}\text { Test } 1 \\
\text { tot }\end{array}$ & $\begin{array}{l}\text { Test } \\
2 \text { tot }\end{array}$ \\
\hline $\mathrm{E}$ & 1 & & & & & & & & & \\
\hline I & -0.9938 & 1 & & & & & & & & \\
\hline S & -0.4025 & 0.43772 & 1 & & & & & & & \\
\hline$N$ & 0.36707 & -0.3734 & -0.8832 & 1 & & & & & & \\
\hline $\mathrm{T}$ & -0.49 & 0.4545 & 0.39284 & -0.3762 & 1 & & & & & \\
\hline $\mathrm{F}$ & 0.36031 & -0.3081 & -0.3248 & 0.5 & -0.8898 & 1 & & & & \\
\hline J & -0.104 & 0.10973 & -0.0135 & 0.12739 & 0.26609 & -0.1622 & 1 & & & \\
\hline $\mathrm{P}$ & 0.13018 & -0.1293 & 0.01907 & -0.0839 & -0.289 & 0.24115 & -0.9746 & 1 & & \\
\hline $\begin{array}{l}\text { Test } \\
1 \\
\text { tot }\end{array}$ & 0.01071 & -0.0115 & -0.0557 & 0.06793 & 0.22585 & -0.1139 & 0.08282 & 0.00975 & 1 & \\
\hline $\begin{array}{l}\text { Test } \\
2 \\
\text { tot }\end{array}$ & -0.1208 & 0.11728 & -0.0579 & 0.18945 & 0.05187 & 0.18331 & -0.273 & 0.34835 & 0.30609 & 1 \\
\hline
\end{tabular}

Figure 7: Correlation Matrix for entrepreneur respondents

The level of significance for a sample of this size is 0.47140452 . From the correlation matrix (Figure 7), the characteristic combinations with a significant correlation are:

- Introvert (I) and Thinking (T) (0.4545)

- Intuitive (N) and Feeling (F) (0.5)

It appears that the correlation matrix shows that Introversion and Thinking tend to run together in ICT entrepreneurs. If ICT entrepreneurs are Introverts, then they tend to be Thinkers, and if they are Thinkers, then they tend to be Introverts.

The research conducted is constrained by a few limitations. These limitations are:

- The third year students had recently attended entrepreneurial lectures and may have felt that it is favourable to be identified as an entrepreneur. This was possibly the reason for the highly skewed data from the entrepreneurial test 1 .

- The first entrepreneur test's scoring was easy to predict, allowing students to obtain a highly entrepreneurial score if they so desired.

- Due to the male to female ratio within the information systems classes and within the ICT industry as a whole, the number of female respondents in the sample was not substantial enough to allow drawing male/female conclusions with regard to ICT entrepreneurship.

- The sizes of the different groups within the population sample are not even. The entrepreneur group was difficult to locate, as they needed to be in the ICT industry and only have a few years of experience. For future studies, it would be desirable to have more participation from ICT entrepreneurs.

\section{Conclusion}

The objective of this paper was to determine whether or not there is a significant difference in personality types and temperaments between potential ICT entrepreneurs and non potential ICT entrepreneurs. The study also aimed to determine whether males are more likely to be potential entrepreneurs than females. 
The population sample used for this study was comprised of third and fourth year information systems students from the University of Cape Town and current ICT entrepreneurs. Each participant was issued a questionnaire which was comprised of a Keirsey Temperament Sorter (to evaluate personality type), and two tests to determine entrepreneurial ability. All the participants were studying information systems or working in the ICT industry.

Initial exploratory analysis was conducted on the data in order to gain an early indication of the significance of the independent variables. Further analysis of personality characteristics that were found to have a statistically significant relationship with potential entrepreneurial ability was undertaken.

No significant relationship between specific personality types and potential entrepreneurial ability was found (Hypotheses one was therefore rejected.), but it was found that ICT entrepreneurs in South Africa are more likely to be of the adaptable type as opposed to the innovative type. There were two temperaments, namely, Rationals and Idealists, that held a positive relationship with potential entrepreneurs. A large portion of the sample was affected by biased responses in the first entrepreneurial test. Further research is therefore needed to eliminate the bias.

From the data analysed, a positive correlation was noticed between potential ICT entrepreneurs and being male. Due to the low number of female respondents ( 37 females as opposed to 98 males), this correlation could not be statistically proven. The findings are therefore regarded as being inconclusive.

The results of the study provide initial insight into the personality characteristics, which could be used as an indicator of potential ICT entrepreneurial ability.

Further research should be conducted with equal numbers of male and female respondents. In addition the effects of age and race on entrepreneurial ability could be analysed.

\section{References}

Borg, M. O., \& Shapiro, S. L. (1996). Personality type and student performance in principles of economics. The Journal of Economic Education, 27(1 -Winter), 3-25.

Chell, E., Haworth J. M., \& Brearley, S. A. (1991). The entrepreneurial personality: Concepts, cases and categories. London: Routledge.

Chen, J., Zhu, Z., \& Anquan, W. (2005). A system model for corporate entrepreneurship. International Journal of Manpower, 26(6), 529-543.

Deo, S. (2005). Challenges for small business entrepreneurs: A study in the Walka Region of New Zealand. Small Business Advancement National Centre, University of Arkansas. Retrieved from http://www.sbaer.uca.edu/research/icsb/2005/056.pdf

Echols, A., \& Neck, C. (1998). The impact of behaviors and structure on corporate entrepreneurial success. Journal of Managerial Psychology, 13(1/2), 38-46.

Fick, D. S. (2002). Entrepreneurship in Africa: A study of successes. Westport: Quorum Books.

Haliburton, W., Thweatt, M., \& Wahl, N. (1998). Gender differences in personality components of computer science students: A test of Holland's congruence hypothesis. Proceedings of the Twenty-Ninth SIGCSE Technical Symposium on Computer Science Education, 77-81.

Hendriks, K., Nhlapo, M., \& Samodien, N. (2002). The impact of personality in IS team effectiveness. Business Times.

Howorth, C., Tempest, S., \& Coupland, C. (2005). Rethinking entrepreneurship methodology and definitions of the entrepreneur. Journal of Small Business and Enterprise Development, 12(1), 24-40. 
Kaluzniacky, E. (2004). Managing psychological factors in information systems work: An orientation to emotional intelligence. USA: Information Science Publishing.

Keirsey, D., \& Bates, M. (1998). Please understand me II. Prometheus Nemisis Book Company.

Lorek, L. (2001). Elizabeth Carlassare. Retrieved August, 2004 from http://www.eweek.com/article2/0,1759,944887,00.asp

Lyons, M. (1985, August 15). The DP psyche. Datamation.

Ma, H., \& Tan, J. (2006). Key components and implications of entrepreneurship: A 4-P framework. Journal of Business Venturing, 21(5), 704-725.

Markham, G. D., \& Baron, R. A. (2003), Person-entrepreneurship fit: Why some people are more successful as entrepreneurs than others. Human Resource Management Review, 13(2), 281-301. Available April, 2004, at: http://www.sciencedirect.com

Mcquaid, R. (2002), Entrepreneurship and ICT industries: Support from regional and local policies. Regional Studies, 36(8), 909-919.

Oxford University. (2004) Oxford Science Enterprise Centre Entrepreneurial test. Retrieved June, 2004, from http://www.science-enterprise.ox.ac.uk/html/Default.asp

Pittenger, D. J. (1993). The utility of the Myers-Briggs Type Indicator. Review of Educational Research, 63(4 - Winter), 467-488.

Reynierse, J. H. (1997). An MBTI model of entrepreneurism and bureaucracy: The psychological types of business entrepreneurs compared to business managers and executives. Journal of Psychological Type, 40, 3-19.

Reynierse, J. H. (2000). The effects of personality and management role on perceived values in business settings. International Journal of Value-Based Management, 13, 1-13.

Richardson T. (2004). Why aren't more women in ICT? The Register. Retrieved October, 2007, from http:/www.theregister.co.uk/2004/08/13/eoc study/

Rwigema, H. \& Venter, R. (2004). Advanced entrepreneurship. Oxford University Press.

Schwalbe, K. (2006). Information technology project management (4th ed.). Canada: Thomson.

Seeda. (2005). Surge in number of female entrepreneurs in the south east. Retrieved January 2008, from http://www.seeda.co.uk/news_\&_events/press_releases/2005/20050208.asp

Sha, S. (2006). An investigation into problems facing small-to-medium sized enterprises in achieving growth in the Eastern Cape: Enhancing the strategy for developing small 'growth potential' firms in the Eastern Cape. Masters thesis, Rhodes University.

Stanford University. (2004). Online Women's Business Center Entrepreneurial Test. Retreived June, 2004 from www.stanford.edu

Startups. (2004). Number of female entrepreneurs hits record levels. Retrieved January 2008 from http://www.startups.co.uk/6678842910901345139/number-of-female-entrepreneurs-hits-record$\underline{\text { levels.html }}$

Teltscher, S. (2002). Gender, ICT and development. Background note to the presentation given at the World Civil Society Forum Geneva, 14-19 July 2002

Timmons, J. A. (1999). New venture creation: Entrepreneurship for the 21st Century (5th ed.). New York: McGraw-Hill International Editions.

Ward, T. B. (2004), Cognition, creativity, and entrepreneurship. Journal of Business Venturing, 19(2), $173-$ 188, Available April, 2004, from http://www.sciencedirect.com

Werth, L. H. (1986). Predicting student performance in a beginning computer science class. Proceedings of the 17th SIGCSE symposium on Computer science education, ACM SIGCSE Bulletin, 18(1). 


\section{Biographies}

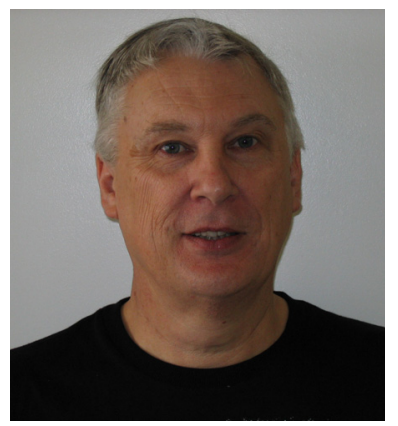

Kevin Johnston is currently senior lecturer and Head of Department of the Department of information Systems at the University of Cape Town (UCT), South Africa. He taught Mathematics \& Science at High Schools before working for 24 years in industry for companies such as Wilson-Rowntree, De Beers, Liberty Life, Lifegro (Legal \& General Volkskas) and BoE in South Africa and Botswana. Kevin joined UCT in 2001 as Senior Lecturer in the Department of Information Systems. His main areas of interest are ICT Management and Project Management.

Barry Andersen, Jennifer Davidge-Pitts, and Mark Ostensen-Saunders were IS Honours students studying the University of Cape Town.

Barry Kurt Andersen completed his studies at the University of Cape Town (UCT), South Africa in 2004. Barry is currently employed by Syncophy Computer Systems.

Jennifer Davidge-Pitts completed her studies at the University of Cape Town (UCT), South Africa in 2004. Jennifer is currently working in $5^{\text {th }}$ Avenue New York for Allen \& Company.

Mark Ostensen-Saunders graduated from the University of Cape Town, South Africa with an Honours degree in Information Systems in 2004. 